\title{
Awareness, Attitude, and Acceptability for Abortion Law among MTP Seekers at a Tertiary Care Center of East Delhi
}

\author{
Richa Sharma ${ }^{1}$, Gita Radhakrishnan ${ }^{2}$, Anita Mehdiratta ${ }^{3}$, Rashmi Gupta ${ }^{4}$
}

\begin{abstract}
Introduction: Termination of pregnancy has been prohibited by law in many countries, but in India induced abortion is legal, under the medical termination of pregnancy act (MTP) 1971. Despite the emergence of health services and availability of legal abortions, estimated 22 million abortions continue to be performed each year unsafely, resulting in the mortality of almost 47,000 women and morbidity for 5 million women due to ignorance amongst women. This study was done to evaluate the level of awareness, attitude and acceptability abortion law among MTP seekers at a tertiary care center.

Materials and methods: Structured questionnaire-based interview schedules were used to assess the awareness, attitude, and acceptability of the MTP seekers.

Results: About 95.4\% and 31.6\% have a vague idea about the gestational limit and indication for MTP. $87.8 \%$ had the preference for Government hospital only because of the "low cost of treatment". $45.5 \%$ preferred only lady doctor and $83.6 \%$ felt that husband's consent is mandatory for MTP. $13.7 \%$ of women were aware that it is legal under certain circumstances.

Discussion: Women should be motivated to overcome socioeconomic and religious barriers and adopt effective contraception. Mass media should be made more informative and effective regarding safe abortion (gestational limit, person, place), usage of emergency contraception, mifepristone, and misoprostol for early abortion and discourage delay in decision making for MTP.

Keywords: Abortion, Emergency contraception, IUD, Public health.

Journal of South Asian Federation of Obstetrics and Gynaecology (2019): 10.5005/jp-journals-10006-1676
\end{abstract}

\section{INTRODUCTION}

Among the 208 million women estimated to become pregnant each year worldwide, 59\% (or 123 million) experience a planned pregnancy leading to birth or abortion or stillbirth. ${ }^{1}$ The remaining $41 \%$ (or 85 million) of pregnancies are unwanted. It has been estimated that 621,748 abortions were performed in 2011-2012, and the number increased slightly to 636,306 in 2012-2013, indicating an annual rate of about two abortions per 1,000 women aged $15-49$ in $2013 .^{2}$

Termination of pregnancy has been prohibited by law in many countries, but in India induced abortion is legal under the Medical Termination of Pregnancy (MTP) Act 1971. A woman can seek induced abortion if the pregnancy is the result of contraceptive failure, rape, carries the risk of grave injury to the physical or mental health of the pregnant women and if there is a substantial risk that the child if born, would suffer from physical or mental abnormalities leading to serious handicap. ${ }^{3}$

Since past more than four decades, there has been an emergence of health services and availability of legal abortions under MTP Act, thereby providing safe, comprehensive abortion care. Medical abortion using mifepristone and misoprostol for safe pregnancy termination at early gestation, and usage of emergency contraception for unprotected intercourse are easily available in our country. ${ }^{4,5}$ Despite these advances, an estimated 22 million abortions continue to be performed unsafely each year, resulting in the mortality of almost 47,000 women and morbidity for 5 million women due to ignorance amongst women. ${ }^{6}$

Termination of an unplanned pregnancy can lead to various physical, emotional and psychiatric disturbances which are the result of a lack of knowledge of contraception. Evidence suggests that
${ }^{1}$ Department of Obstetrics and Gynaecology, University College of Medical Sciences, Dilshad Garden, New Delhi, India

${ }^{2}$ Department of Obstetrics and Gynaecology, University College of Medical Sciences, University of Delhi, Delhi, India

3,4 Department of Obstetrics and Gynaecology, University College of Medical Sciences and Guru Teg Bahadur Hospital, University of Delhi, Delhi, India

Corresponding Author: Richa Sharma, Department of Obstetrics and Gynaecology, University College of Medical Sciences, Dilshad Garden, New Delhi, India, e-mail: gautamdrricha1@gmail.com

How to cite this article: Sharma R, Radhakrishnan G, et al. Awareness, Attitude, and Acceptability for Abortion Law among MTP Seekers at a Tertiary Care Center of East Delhi. J South Asian Feder Obst Gynae 2019;11(2):120-125.

Source of support: Nil

Conflict of interest: None

abortion rates are lowest in those countries with a comprehensive system of sex education and contraceptive services. Almost all deaths and disabilities could have been prevented through adequate knowledge or awareness regarding safe legal abortion and adoption of reliable contraceptives.

The present study was designed to probe into the awareness, attitude, and acceptability among MTP seekers.

\section{Aıм}

To evaluate the level of awareness, attitude and acceptability for abortion law among MTP seekers at a tertiary care teaching hospital.

() The Author(s). 2019 Open Access This article is distributed under the terms of the Creative Commons Attribution 4.0 International License (https://creativecommons. org/licenses/by-nc/4.0/), which permits unrestricted use, distribution, and non-commercial reproduction in any medium, provided you give appropriate credit to the original author(s) and the source, provide a link to the Creative Commons license, and indicate if changes were made. The Creative Commons Public Domain Dedication waiver (http://creativecommons.org/publicdomain/zero/1.0/) applies to the data made available in this article, unless otherwise stated. 


\section{Materials and Methods}

A cross-sectional study was conducted for six months among eligible MTP seekers in the Family Planning Unit of the Department of Obstetrics and Gynaecology of our institution, irrespective of their age, parity, marital, socioeconomic and demographic status. Prior ethical clearance was obtained from the Institutional Ethical Committee.

Women not giving consent for the interview were excluded from the study.

MTP was done as per our institution protocol (based on WHO 2012 and FIGO recommendations). Women could opt for:

- Medical method of abortion on OPD basis for gestational age less than 7 weeks (D1-an oral dose of the tab. Mifepristone $200 \mathrm{mg}$, D3 tab. Misoprostol $\mu \mathrm{g} 400$ orally or $800 \mu \mathrm{g}$ vaginally

- Suction and evacuation in the first trimester

- Second-trimester abortion (D1-tab mifepristone 200 mg orally, D3 misoprostol $400 \mu \mathrm{g}$ vaginally or sublingually 3-hourly (5 doses max).

A structured questionnaire was devised that included the information on age of couple, religion, marital status, education, socioeconomic level, prior medical/surgical or psychiatric history, total number of children, number of girl child, obstetric history along with current and previous abortions (reason, method and complications), contraception usage, awareness about legal abortion (reason for opting tertiary centre, MTP types, method, indication, place, person, associated complications, choice of doctor, abortion laws, source of information) etc.

These structured questionnaire based interview schedules were used to assess the awareness, attitude and acceptability of these women at the time of admission (for the women seeking surgical method of MTP and Medical method for mid-trimester abortions) and at the time of allotment of MTP numbers (those opting for medical method of abortion for early pregnancies up to 7 weeks on OPD basis).

\section{Results}

Two hundred thirty-four women were enrolled for the study and 38 were lost to follow up, so the remaining 196 women completed the study.

Majority of the women 76 (38.8\%) belonged to $26-30$ years of age and the mean spousal age was 5.4 years (Fig. 1).

Fourteen (7.1\%) were primigravida, $148(75.5 \%)$ multigravida and 34 (17.3\%) were grandmulti. Hindu women were 168 (85.7\%) and only $2(1 \%)$ were Christians. Divorced and unmarried constituted 2 (1\%) each as compared to married women 192 (98\%). Educational status was satisfactory, 144 (73.4\%) were literate and 52 (26.5\%) were illiterate (Fig. 2).

Majority 175 (89.2\%) of the women were housewives, 19 (9.7\%) were working women (laborer, business, private or government job, health professional) and 2 (1\%) were students (Fig. 3).

Mean monthly income was Rs. $10005.10 \pm 9871.22$.

Out of 196 MTP seekers, 29 (14.8\%) were in the 2nd trimester, 48 (24.5\%) belonged to early gestation $<7$ weeks and $119(60.7 \%)$ women were between $7+1$ and 12 weeks gestation. Suction and evacuation were opted by the majority of the women 153 (78\%), followed by the medical method of abortion for early gestation on an OPD basis 48 (24.5\%) and 2nd-trimester medical abortion $29(14.8 \%)$.

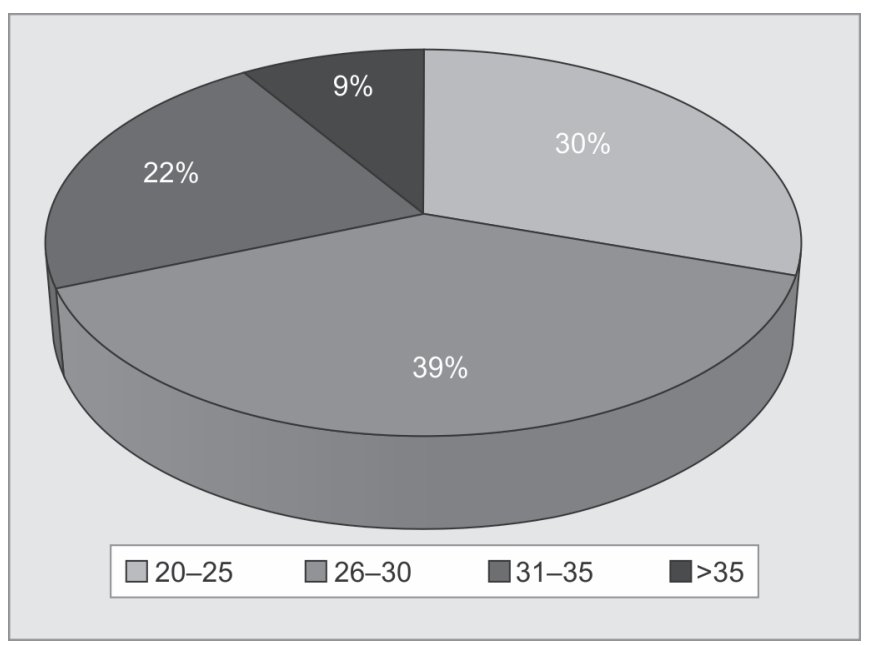

Fig. 1: Age distribution

Common indications for MTP were completed family size 135 (68.9\%) (out of which 53 women irregularly used contraceptives and 82 did not use), contraception failure 23 (11.7\%), maternal illness 10 (5.1\%) (5 women had pulmonary Koch's, 1 had urogenital TB, 3 had HIV and 1 had breast carcinoma), birth spacing (not used any contraceptives) 15 (7.6\%), ligation failure 1 (0.5\%).

The most common concurrent contraception opted was lap ligation 92 (46.9\%), and it was not advised for 2 women as their pregnancies were due to sexual assault. Barrier contraception was advised for 10 (5.1\%) women who had congenital fetal malformations and 1 woman with tuberculosis in their index pregnancies.

Minor complications were observed in 74 (37.7\%) women that included nausea, vomiting, abdominal cramps and irregular bleeding (retained products- requiring D\&C). Major complication observed was uterine perforation, 2 (1\%) women were kept on conservative management, and $4(2 \%)$ required laparotomy for bowel exploration; however, none of them had any bowel injury. Rest of $13(6.6 \%)$ laparotomies were done due to intraoperative complications during lap ligations (Table 1).

Awareness about legal abortion among MTP seekers was deficient, only 9 (4.6\%) women were aware that MTP can be done up to 5 th month of pregnancy and 187 (95.4\%) women had a vague idea that it can be terminated at any gestation age. One hundred sixty-four (83.6\%) women thought that husband or parent's consent is mandatory for MTP while $11(5.6 \%)$ had the knowledge that only woman's consent is required provided that she is major and mentally sound. Awareness about emergency contraceptives was only 6 (3\%) vs 190 (96.9\%). Only 55 (28\%) women had some idea about surgical or medical methods of MTP. One hundred twentyone (61.7\%) never knew that some minor or major complications can occur in safe abortions, while 30 (15.3\%) women were aware of a few complications including uterine perforation.

Although India has made abortions legal under MTP act 1971, majority of the women 169 (86.2\%) consider it illegal and criminal but they said: "we have no choices but to commit sin". Only $27(13.7 \%)$ women were aware that it is legal under certain circumstances and this they attributed to newspaper $10(5.1 \%)$, neighbours $6(3.1 \%)$, family or relatives $5(2.6 \%)$, health workers 6 (3.1\%) for their source of information (Table 2).

Regarding attitude towards MTP, 178 (90.8\%) women agreed for legal abortion and the common indications quoted were completed 


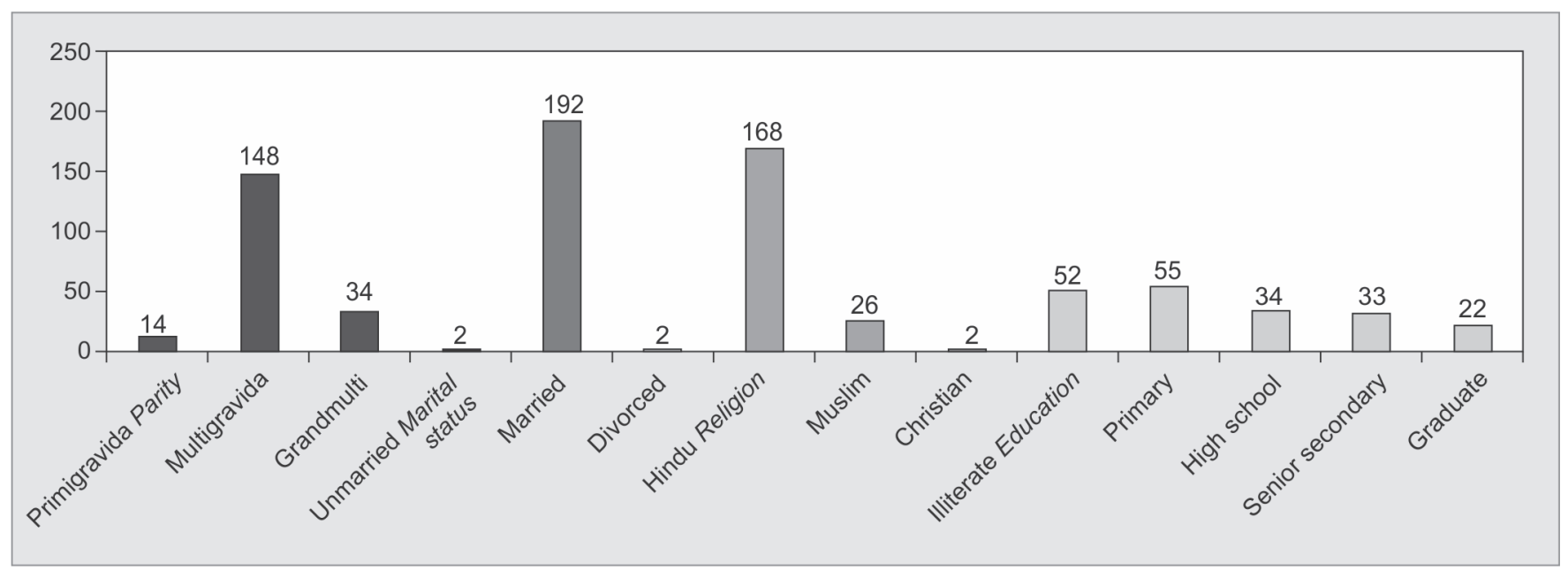

Fig. 2: Sociodemographic profile

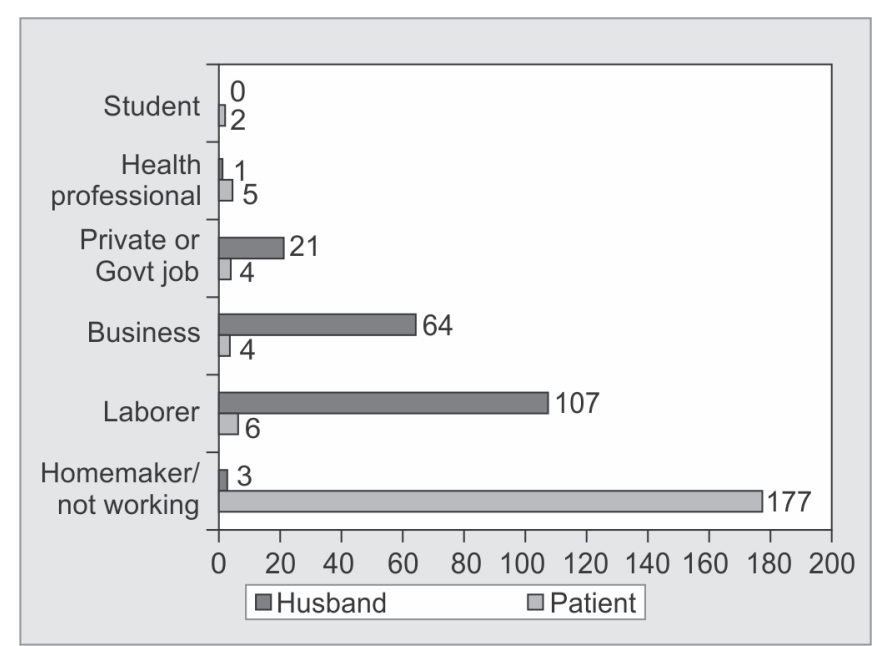

Fig. 3: Occupation of patient and spouse

family size or contraception failure 18 (9.2\%), birth spacing 5 (2.6\%), malformed fetus 8 (4\%), maternal illness 14 (7.1\%), extramarital or rape $3(1.5 \%)$ and $86(43.8 \%)$ women agreed for any of the above reasons provided that the mother is safe. 62 (31.6\%) women were not sure.

One hundred seventy-two (87.8\%) women preferred a government set up for MTP, and the only reason given was 'free of cost', 15 (7.7\%) women preferred any Government approved center, 6 (3.1\%) wanted Private clinic as "they do not want to wait for the queue" and 3 (1.5\%) were not sure. Although 89 (45.5\%) women preferred lady doctor only but the majority of the women 103 (52.6\%) did not discriminate between male or female doctors and they preferred any male or female certified doctor.

One hundred seventy-nine (91.3\%) women had the positive attitude towards concurrent contraception, 84 (42.8\%) women voted for tubectomy, 82 (41.8\%) copper T, 8 (4.1\%) OCP and none for a vasectomy. 17 (8.7\%) Muslim women did not agree for its due to their religious taboos.

One hundred seventy-two (87.7\%) women expressed their attitude that husband's consent should be taken before MTP so that "they have more sense of responsibility and take care of their wives".
Table 1: Current MTP status

\begin{tabular}{|c|c|}
\hline & No. of women (\%) \\
\hline \multicolumn{2}{|l|}{ Period of gestation (weeks) } \\
\hline$<7$ & $48(24.5)$ \\
\hline $7+1$ to 12 & $119(60.7)$ \\
\hline$>12+1$ & $29(14.8)$ \\
\hline \multicolumn{2}{|l|}{ Mode of termination } \\
\hline $\begin{array}{l}\text { Medical method for early gestation } \\
\text { ( }<7 \text { weeks) }\end{array}$ & $14(7.1)$ \\
\hline Suction and evacuation in 1st trimester & $153(78)$ \\
\hline 2nd trimester (medical method) & $29(14.8)$ \\
\hline \multicolumn{2}{|l|}{ Indication of MTP } \\
\hline Contraception failure & $23(11.7)$ \\
\hline Family completed & $135(68.9)$ \\
\hline Women irregularly used contraceptives & $53(39.2)$ \\
\hline Did not use contraceptives & $82(60.7)$ \\
\hline Malformed fetus & $10(5.1)$ \\
\hline Sexual assault & $2(1)$ \\
\hline Material illness & $10(5.1)$ \\
\hline Birth spacing (not used any contraceptives) & $15(7.6)$ \\
\hline Ligation failure & $1(0.5)$ \\
\hline \multicolumn{2}{|l|}{ Concurrent contraception done } \\
\hline OCP & $3(1.5)$ \\
\hline Copper T & $72(36.7)$ \\
\hline Lap ligation & $92(46.9)$ \\
\hline Minilap & $16(8.2)$ \\
\hline None & $13(6.6)$ \\
\hline \multicolumn{2}{|l|}{ Complications } \\
\hline Nausea, vomiting & $54(27.5)$ \\
\hline Abdominal cramps & $18(9.1)$ \\
\hline $\begin{array}{l}\text { Severe bleeding requiring D\&C (soaking }> \\
2 \text { thick pads/hour for } 2 \text { consecutive hours) }\end{array}$ & 0 \\
\hline Retained products & $2(1)$ \\
\hline Uterine perforation (conservative) & $2(1)$ \\
\hline Uterine perforation (laparotomy done) & $4(2)$ \\
\hline \multicolumn{2}{|l|}{ Laprotomy } \\
\hline Tubes avulsed on lap & $5(2.6)$ \\
\hline Failed lap due to adhesions) & $7(3.6)$ \\
\hline Suspected bowel injury on lap) & $1(0.5)$ \\
\hline
\end{tabular}


Table 2: Awareness of MTP

\begin{tabular}{ll}
\hline Parameter & No. (\%) \\
\hline Correct knowledge of gestational limit & \\
Aware & $9(4.6)$ \\
Not aware & $187(95.4)$ \\
Not sure & $21(10.7)$ \\
Consent of husband required & \\
Aware & $164(83.6)$ \\
Not aware & $11(5.6)$ \\
Not sure & $21(10.7)$ \\
Awareness of methods & \\
Medical & $3(1.5)$ \\
Surgical & $2(1)$ \\
Both & $50(25)$ \\
None & $141(71.9)$ \\
Awareness of postabortion complications & \\
Abdominal pain & $18(9.2)$ \\
Bleeding & $16(8.2)$ \\
Retained products & $1(0.5)$ \\
Infections & $6(3.1)$ \\
Uterine perforation & $4(2)$ \\
All & $30(15.3)$ \\
Do not know & $121(61.7)$ \\
Aware of emergency contraceptives & \\
Aware & $6(3)$ \\
Not aware & $190(96.9)$ \\
Awareness of legal aspect/abortion law & $6(2.6)$ \\
Heare & $169(86.2)$ \\
Dource of informath workers & $169(86.2)$ \\
News paper & \\
\hline
\end{tabular}

150 (76.5\%) women shared their abortion experiences with their relatives and friends, out of which 146 (97.3\%) women expressed a positive attitude toward MTP (Table 3 ).

178 (90.8\%) women were satisfied with the MTP service at our Hospital, 18 (9.2\%) were not satisfied, and the reasons were prolonged hospital stay [failed lap and converted to mini-lap 7 (3.5\%), uterine perforation and laparotomy was done $2(1 \%)]$ and multiple hospital visits (medical method of abortion for early gestation on OPD basis 9 (4.5\%). Women in S\&E group (142/153) and $6 / 14$ women in MMA group expressed themselves to repeat the same procedure and would recommend it to others. However, out of $30(15.5 \%)$ women who had experienced both the procedures, 23 preferred S\&E.

It was surprising to know that maximum emotional support for MTP seekers was obtained by their mothers 91 (46.4\%), relatives/neighbors 51 (26\%) and least by their husbands 48 (24.4\%).

Despite various family planning programs being launched, contraceptive usage was low among MTP seekers and only 76
Table 3: Attitude

\begin{tabular}{|c|c|}
\hline Parameter & No. (\%) \\
\hline \multicolumn{2}{|l|}{ Personal opinion regarding abortion } \\
\hline \multicolumn{2}{|l|}{ Should MTP be done } \\
\hline Yes & $178(90.8)$ \\
\hline No & $2(1)$ \\
\hline Not sure & $16(8.1)$ \\
\hline \multicolumn{2}{|l|}{ Reasons believed for MTP } \\
\hline Completed family only & $18(9.2)$ \\
\hline Want a child later/birth spacing & $5(2.6)$ \\
\hline Malformed fetus & $8(4)$ \\
\hline Health illness & $14(7.1)$ \\
\hline Premarital/rape & $3(1.5)$ \\
\hline Any & $86(43.8)$ \\
\hline Not sure & $62(31.6)$ \\
\hline \multicolumn{2}{|l|}{ Choice of place } \\
\hline Home & 0 \\
\hline Private clinic & $6(3.1)$ \\
\hline Government set up only & $172(87.8)$ \\
\hline Any government approved centre & $15(7.7)$ \\
\hline Not sure & $3(1.5)$ \\
\hline \multicolumn{2}{|l|}{ Choice of person } \\
\hline Dias & $3(1.5)$ \\
\hline Elderly family members & $1(0.5)$ \\
\hline Lady doctor only & $89(45.5)$ \\
\hline Male or Female certified government & $103(52.6)$ \\
\hline \multicolumn{2}{|c|}{ Should MTP be followed by concurrent contraception } \\
\hline Yes & $179(91.3)$ \\
\hline No & $17(8.7)$ \\
\hline \multicolumn{2}{|l|}{ Types } \\
\hline Barrier & $2(1)$ \\
\hline OCP & $8(4.1)$ \\
\hline IUCD & $82(41.8)$ \\
\hline Tubectomy & $84(42.8)$ \\
\hline Vasectomy & 0 \\
\hline Any & $3(1.5)$ \\
\hline \multicolumn{2}{|l|}{ Should husband consent be taken } \\
\hline Yes & $172(87.7)$ \\
\hline No & $24(12.2)$ \\
\hline \multicolumn{2}{|l|}{ Decision for abortion } \\
\hline Self only & $2(1)$ \\
\hline Husband only & 0 \\
\hline Self and husband & $191(97.4)$ \\
\hline Mother/mother in law & $(1.5)$ \\
\hline \multicolumn{2}{|l|}{ Shared abortion experience } \\
\hline Yes & $150(76.5)$ \\
\hline No & $46(23.4)$ \\
\hline Positive & $146(97.3)$ \\
\hline Negative aspects & $4(2.7$ \\
\hline
\end{tabular}

(38.8\%) women used it and 120 (61.2\%) women never used any contraceptives in their lifetime. Oral contraceptive pills were most widely accepted 35 (46\%), followed by condoms 29 (38.1\%) and copper T 9 (11.8\%). About $36.8 \%$ of women had irregular contraception usage. 


\begin{tabular}{|c|c|}
\hline Parameter & No. (\%) \\
\hline \multicolumn{2}{|l|}{ Satisfied with MTP service } \\
\hline Satisfied & $178(90.8 \%)$ \\
\hline Not satisfied & $18(9.2 \%)$ \\
\hline $\begin{array}{l}\text { Will accept the same method again suction } \\
\text { and evacuation }(n=153)\end{array}$ & 142 (92.8\%) \\
\hline Medical methods $(n=14)$ & $6(42.8 \%)$ \\
\hline \multicolumn{2}{|l|}{$\begin{array}{l}\text { Women underwent medical and surgical } \\
\text { method }(n=30)\end{array}$} \\
\hline Preferred medical method & $7(23.3 \%)$ \\
\hline Preferred surgical method & $23(76.6 \%)$ \\
\hline \multicolumn{2}{|l|}{ Emotional support } \\
\hline Husband & $48(24.4 \%)$ \\
\hline Mother & $91(46.4 \%)$ \\
\hline Relatives/neighbours & $5126 \%)$ \\
\hline None & $6(3 \%)$ \\
\hline \multicolumn{2}{|l|}{ No. previous induced abortion } \\
\hline 1 & $22(11.2 \%)$ \\
\hline 2 & $8(4.1 \%)$ \\
\hline$\geq 3$ & 0 \\
\hline Total & $30(15.3 \%)$ \\
\hline \multicolumn{2}{|l|}{ History of previous induced abortion } \\
\hline \multicolumn{2}{|l|}{ Indication } \\
\hline $\begin{array}{l}\text { Family completed and contraception } \\
\text { failure }\end{array}$ & $9(30 \%)$ \\
\hline Maternal illness & $4(13.3 \%)$ \\
\hline Birth spacing & $16(53.3 \%)$ \\
\hline Malformed fetus & $1(0.5 \%)$ \\
\hline \multicolumn{2}{|l|}{ Method } \\
\hline Medical & $7(23.3 \%)$ \\
\hline Surgical & $23(76.6 \%)$ \\
\hline \multicolumn{2}{|l|}{ Place } \\
\hline Home & 0 \\
\hline Dispensary & $4(13.3 \%)$ \\
\hline Private clinic & $9(30.0 \%)$ \\
\hline Government hospital & $4(33.3 \%)$ \\
\hline \multicolumn{2}{|l|}{ Complications } \\
\hline Abdominal pain & $18(60 \%)$ \\
\hline Severe bleeding (requiring $D \& C$ ) & $3(10 \%)$ \\
\hline $\begin{array}{l}\text { Irregular bleeding (retained products, } \\
\text { D\&C done) }\end{array}$ & $4(13.3 \%)$ \\
\hline Infections & $2(6.6 \%)$ \\
\hline \multicolumn{2}{|l|}{ Previous contraception usage } \\
\hline Never used & $120(61.2 \%)$ \\
\hline Used & $76(38.8 \%)$ \\
\hline \multicolumn{2}{|l|}{ Type } \\
\hline Barrier & $29(38.1 \%)$ \\
\hline OCP & $17(22.3 \%)$ \\
\hline Barrier switched to OCP & $12(15.7 \%)$ \\
\hline IUCD switched to OCP & $6(7.8 \%)$ \\
\hline IUCD & $9(11.8 \%)$ \\
\hline Natural & $2(2.6 \%)$ \\
\hline Failed ligation & $1(1.3 \%)$ \\
\hline
\end{tabular}

\begin{tabular}{ll} 
Contd... & \\
\hline Parameter & No. (\%) \\
\hline Duration of contraception usage & \\
$\quad<1$ year & $14(18.4 \%)$ \\
$1-3$ years & $15(19.7 \%)$ \\
$3-5$ years & $9(11.8 \%)$ \\
$>5$ years & $10(13.10)$ \\
Irregularly & $28(36.8 \%)$ \\
Addiction following abortion & \\
Tea/coffee & $23(11 \%)$ \\
Smoking & $6(3 \%)$ \\
Alcohol & 0 \\
None & $167(85.2 \%)$ \\
\hline
\end{tabular}

Among 196 women 30 (15.3\%) had a history of previous induced abortions, $22(11.2 \%)$ had one, and 8 (4.1\%) had two abortions. Common indications being Birth Spacing 16 (53.3\%) and contraception failure. 23 (76.6\%) women underwent surgical methods, by Dias 6 (20\%), by nurses in the dispensary $4(13.3 \%)$, Private clinic 9 (30\%) and government hospital 4 (33.3\%). Severe bleeding that required dilatation and curettage and blood transfusion occurred in $3(10 \%)$ women, irregular bleeding attributed to retained products and required D\&C in $4(13.3 \%){ }^{2}$ (6.6\%) women suffered from postabortal sepsis and prolonged hospital stay (Table 4).

\section{Discussion}

National family planning program had been launched in 1589 and since then various changes and modifications have been made. Sadly, despite the availability of safe and effective contraception, emergency contraception, mifepristone and misoprostol, and safe abortion services, women continue to have unwanted pregnancy because the need for it has not been met, mainly due to lack of awareness.

Umashanker et al. ${ }^{3}$ evaluated the knowledge and attitude of 105 MTP seekers in South India. Most common indications for MTP were unplanned pregnancy (55.25\%) and contraception failure (44.7\%). $42.5 \%$ of women never used any contraception.10\% women were aware of the medical method of abortion for early pregnancy termination, and $1.5 \%$ had the knowledge of emergency contraceptives. Concurrent contraception accepted were intrauterine devices $(51.5 \%)$, followed by permanent sterilization (24.7\%).

A cross-sectional study conducted on 152 women by Gupta et al., found that common indication for MTP was completed family (63.16\%) and birth spacing (20.4\%). Concurrent contraception opted were tubal ligation (64\%) and copper T (34\%). Only $5.26 \%$ of women were aware of emergency contraception. Majority of MTP seekers (84.21\%) had more than 2 children and two third women $(68.42 \%)$ had repeat MTP within 2 years. This indicated that despite completing the desired family size women continued to have unwanted pregnancies and their terminations, probably due to poor awareness and adoption of contraceptives. ${ }^{6}$

Sharma et al. observed that $26.72 \%$ women never used any contraception and common reasons were fear of side effects (29.03\%), restriction by religious belief $(12.90 \%)$ and male gender bias (9.67\%). Among the MTP seekers, $73.27 \%$ of women had $2-5$ children and $2.58 \%$ had more than 5 children. These unintended pregnancies getting terminated highlights the unmet needs. ${ }^{7}$ 
The present study observed that the commonest indication for MTP was completed family size (68.9\%) and $60.7 \%$ of these women never used any contraceptives. Majority of the women opted for tubectomy (46.9\%) as concurrent contraception, and only $3 \%$ were aware of emergency contraceptives.

Ghana health service reported that $3 \%$ of women were aware that abortion is legal, 54\% did not know anything, and 43\% thought that it is illegal. Regarding awareness about the gestational age limit for MTP, $51 \%$ of women believed within the first 4 months, and $34 \%$ had no idea about it. Unsafe abortion complications quoted were mortality (34\%), infertility (35\%) and infections $23 \% .^{8}$

Gupte et al. conducted a study on Indian rural women and quoted that $18 \%$ knew that abortion is legal in India, $64 \%$ illegal and $16 \%$ were not sure. Awareness about gestational age cut off was inadequate, $50 \%$ knew that abortion was done up to the 5 th month in government hospitals, 11 women felt that during first trimester, 6 and 14 women thought even in the third trimester it can be done in public and private hospitals respectively, 20 women were unsure. Nine women believed that husband consent is mandatory. ${ }^{9}$

In our study, $13.7 \%$ of women were aware that abortion is legal in India and only $4.6 \%$ knew the gestational limit for MTP. $83.6 \%$ of women thought that the husband's consent is mandatory.

Forty-six percent of Ghana women felt that abortion should not be practiced and out of this $87 \%$ considered it a sin. Reasons believed for termination of pregnancies were rape, $62 \%$ endangering physical or mental health of women $35 \%$, incest $35 \%$, risk of fetal congenital anomalies $31 \%$. Women preferring medical doctors were $73 \%$, gynecologist $19 \%$ and trained nurses $4 \%$ or midwife. $65 \%$ of women preferred government hospitals for abortion due to cost-effectiveness, $36 \%$ private and $12 \%$ any convenient place. ${ }^{8}$

Indian rural women believed that abortion is a crime and could lead to sterility, while others considered it for spacing the pregnancies. All the women preferred lady gynecologist and hospital-based MTP. Thirteen wanted husbands to consent on the forms so that they become more considerate to their wives but 9 women felt that it should not be required as husbands are not available most of the time. ${ }^{10}$

Our study also found that MTP seekers preferred government hospital for an abortion, but $52.6 \%$ were comfortable with any certified male or female doctors. $87.7 \%$ wanted a husband's consent for a similar reason.

Eleven percent of women had an abortion earlier, and 38\% suffered some complications like abdominal cramps, mild to severe bleeding, retained products of conceptions and weakness. ${ }^{9}$

Woldetsadik et al. observed that $91.2 \%$ vs $82 \%$ women in the medical method of abortion (MMA) and manual vacuum aspiration (MVA) groups respectively were satisfied with the methods. An 83.3\% in MMA and $77.4 \%$ women in MVA groups would choose the same procedure again, $94 \%$ of women in medical abortion vs $86.8 \%$ MMA would suggest their friend the same methods. ${ }^{10}$
Urquhart and Templeton reported that method of abortion was acceptable to $75 \%$ women in medical and $94 \%$ in surgical groups. Among the women who experienced both the methods in their lifetime, $77 \%$ preferred medical method over surgical. ${ }^{11}$

The present study observed that $90.8 \%$ were satisfied with the MTP services at the Tertiary care teaching Hospital.

\section{Conclusion}

Safety of abortion depends on awareness, attitude, and acceptability for it. Women should be discouraged to conceal their past obstetric and medical history at the time of MTP which could lead to untoward complications. Mass media should be made more informative and effective regarding safe abortion (gestational limit, person, place), usage of emergency contraception, mifepristone, and misoprostol for early abortion and discourage delay in decision making for MTP. Women should be motivated to overcome socioeconomic and religious barriers and adopt effective contraception.

\section{References}

1. Singh $S$, Wulf $D$, et al. Abortion worldwide: a decade of uneven progress. New York: Guttmacher Institute; 2009. Available from: https://www.guttmacher.org/pubs/Abortion-Worldwide.pdf. Accessed on 10th March 2016.

2. World Health Organization, Department of Reproductive Health and Research. Safe abortion: technical and policy guidance for health systems. 2nd ed., Geneva: WHO; 2012.

3. Umashankar KM, Dharmavijaya MN, et al. Survey of the attitude to, the knowledge and the practice of contraception and medical abortion in women who attended a family planning clinic. Clin Diagn Res 2013;7(3):493-495.

4. Medical Termination of Pregnancy act. Ministry of Health and Family Welfare 2003.

5. Åhman E, Shah I. Unsafe abortion: global and regional estimates of the incidence of unsafe abortion and associated mortality in 2008. 6th ed., Geneva: World Health Organization; 2011.

6. Gupta S, Dave V, et al. A study on socio-demographic and obstetric profile of MTP seekers at Guru Govind Singh Hospital. Jamnagar Healthline 2012;3:50.

7. Sharma A, Sharma U, et al. Acceptability and practice of contraception and frequency of induced abortions in married women of reproductive age group, in a tertiary-care hospital. Int J Med Sci Public Health 2015;4(6):845-848. DOI: 10.5455/ijmsph.2015.05012015169.

8. Improvement in abortion and postabortion care services. Ghana Health Services Annual Report 2007.

9. Gupte M, Bandewar S, et al. Abortion needs of women in India: a case study of Rural Maharastra. Reprod Health Matters 1997;9:77-86. DOI: 10.1016/S0968-8080(97)90008-2.

10. Woldetsadik MA, Sendekie TY, et al. Client preferences and acceptability for medical abortion and MVA as early pregnancy termination method in northwest Ethiopia. Reprod Health 2011;8:19. DOI: 10.1186/1742-4755-8-19.

11. Urquhart DR, Templeton AA. Psychiatric morbidity and acceptability following medical and surgical methods of induced abortion. Br JObstet Gynaecol 1991;98(4):396-399. DOI: 10.1111/j.1471-0528.1991.tb13431.x. 